\title{
Shear wave velocity by quantitative acoustic radiation force impulse in the placenta of normal and high-risk pregnancy
}

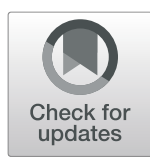

\author{
Mohamed Mohamed Hefeda ${ }^{*}$ (D) and Alshymaa Zakaria
}

\begin{abstract}
Background: Traditionally, the placental functional integrity is suggested by indirect ultrasound measurements like fetal growth, amniotic fluid index, and uterine and umbilical artery Doppler indices. Only recently the elasticity of the placenta is studied as a measure of placental consistency and biomechanical prosperities and may reflect the placental function. Shear wave velocity is the quantitative parameter of the shear wave elastography. A high-risk pregnancy is a situation which puts the mother, the fetus, or both at greater risk than a normal pregnancy.

Results: The shear wave velocity (SWV) showed no significant difference between the placenta of normal pregnancies in the second and third trimesters $(0.85 \pm 0.43 \mathrm{~m} / \mathrm{s}$ and $0.89 \pm 0.57 \mathrm{~m} / \mathrm{s}$, respectively). The placenta of patients with preeclampsia/eclampsia had high SWV in the second and third trimesters $(2.13 \pm 1.48 \mathrm{~m} / \mathrm{s}$ and $2.23 \pm$ $1.48 \mathrm{~m} / \mathrm{s})$ with a highly significant difference from the normal placenta $(P<0.001)$. The placentas with abnormal location (placenta previa) and penetration (placenta accreta) had higher SWV than the placenta of normal pregnancies. The mean SWV for placenta previa was $1.1 \pm 0.74 \mathrm{~m} / \mathrm{s}$ and $1.3 \pm 0.81 \mathrm{~m} / \mathrm{s}$ in the second and third trimesters, respectively, with a mildly significant difference with the normal placenta. The placenta accreta shows high mean SWV in the second and third trimesters $(1.6 \pm 0.65 \mathrm{~m} / \mathrm{s}$ and $1.961 .6 \pm 0.65$, respectively) which differed significantly $(P<0.001)$ from SWV in the normal placenta in the second and third trimesters.

Conclusion: Shear wave velocity measurement as the quantitative parameter of acoustic radiation force impulse (ARFI) elastography reflects the placental elasticity in normal and high-risk pregnancies. The SWV increases in conditions like hypertension, preeclampsia, maternal renal disease, and diabetes and reflects the structural and biomechanical abnormalities in such diseases. High shear wave velocity correlates with the incidence of growth restriction and abnormal Doppler parameters especially in the hypertensive disease. The virtual touch quantification (VTQ) can be used as a complementary diagnostic and prognostic tool in high-risk pregnancy.
\end{abstract}

Keywords: Shear wave elastography, Shear wave velocity, Placenta, Acoustic radiation force impulse, Placental insufficiency, Placenta accreta, Elastography

\section{Background}

The human placenta is the intermediate organ between the mother and fetus characterized by rapid growth and development, and it plays a pivotal role in the fetal oxygenation and nutrition [1]. Traditionally, the placental functional integrity is suggested by indirect ultrasound

* Correspondence: mohamedhefeda@yahoo.com

Radiology Department, Faculty of Medicine, Tanta University, Tanta, Egypt measurements like fetal growth, amniotic fluid index, and uterine and umbilical artery Doppler indices as well as fetal Doppler indices in the middle cerebral artery, fetal aorta, and ductus venosus. Many studies suggested a limited value of ultrasound in screening of small for date newborn and in prevention of maternal or fetal complications [2-4]. The ultrasound and color Doppler ultrasound evaluate the placenta from a hemodynamic prospect, but the placenta can be studied from the

\section{Springer Open}

(๑) The Author(s). 2020 Open Access This article is licensed under a Creative Commons Attribution 4.0 International License, which permits use, sharing, adaptation, distribution and reproduction in any medium or format, as long as you give appropriate credit to the original author(s) and the source, provide a link to the Creative Commons licence, and indicate if changes were made. The images or other third party material in this article are included in the article's Creative Commons licence, unless indicated otherwise in a credit line to the material. If material is not included in the article's Creative Commons licence and your intended use is not permitted by statutory regulation or exceeds the permitted use, you will need to obtain permission directly from the copyright holder. To view a copy of this licence, visit http://creativecommons.org/licenses/by/4.0/. 
biomechanical prospect like other tissues. Relatively, recent studies suggested that the consistency and biomechanical properties of the placenta in cases with placental insufficiency differ from those of the normal placenta and normal pregnancy $[5,6]$.

Elasticity as a physical property means the ability to regain shape after the deforming force is removed. The tissue stiffness reflects the biological and mechanical properties of tissues and may be affected in conditions like inflammation, fibrosis, or neoplasia [7]. Elastography is the relevant tool in studying the elasticity and biomechanical properties of tissues. Elastography has been used in differentiation between benign and malignant tissues in the breast $[8,9]$, thyroid $[10,11]$, and prostate [12], as well as evaluation of liver fibrosis [13-15].

The main elastography techniques are the quasi-static methods and dynamic methods. In the quasi-static methods, a constant stress is applied to the tissue of interest to generate a strain map or elastogram. Several dynamic methods are currently available including vibro-acoustography, acoustic radiation force impuse (ARFI), transient elastography, and shear wave elastography $[16,17]$.

Acoustic radiation force impuse (ARFI), which is a relatively novel technique, provides both qualitative and quantitative measuring of the tissue elasticity. The shear wave velocity (SWV) is the quantitative parameter, which was previously applied in liver, breast, lymph node, and thyroid disease and masses. This method uses acoustic radiation to generate vibrations and then calculate the velocity of the laterally propagated shear waves. This method provides quantitative data in real time and has high reproducibility. The harder the tissue, the higher the velocity $[18,19]$.

A high-risk pregnancy is a situation which puts the mother, the fetus, or both at greater risk than a normal pregnancy. The risk factors include maternal age, hypertension, diabetes, renal impairment, hypo- and hyperthyroidism, morbid obesity, and other diseases.

Several studies have studied the role of elastography in the evaluation of the placenta in small for date pregnancies and preeclampsia. Most studies suggested high shear wave velocities in both conditions. Yet, most was with a limited number of patients with heterogeneous methodology [20-22].

The aim of the current study was to investigate the elasticity of the placenta in normal and high-risk pregnancy using quantitative shear wave elastography (qSWE) and measurement of shear wave velocity (SWV).

\section{Methods}

\section{Patients}

This was a prospective study that was approved by the local ethics committee, and informed consent was signed by all patients. A total of 470 pregnant females were included in the study. One hundred sixty patients were in the second trimester (18 to $<28$ weeks gestation), and the rest (310 patients) were in the third trimester $(28$ weeks or more). The study was conducted from October 2018 to March 2020. The number of patients and mean age of patients in each group are listed in Table 1.

The mean age was $23.5 \pm 6.2$ years (range, 18-37 years) in the second trimester group and $25.3 \pm 7.41$ years (range, 19-42 years) in the third trimester group. We included in the study in each group healthy pregnant females and females with risk factors including abnormal placentas (placenta preavia and placenta accreta). Excluded from the study are females with multiple gestations, patients with severe anemia, and patients with retroplacental hematoma. In the third trimester pregnancy, we could not perform elasticity calculations in most posterior placentas.

\section{Equipment}

We used Acuson S3000 (Siemens, Erlangen, Germany) equipped with a curved probe (4C1 Acuson) for gray-scale, color Doppler, and ARFI elastography measurements.

\section{Gray-scale ultrasound}

Normal fetal measurement and biometry were performed including the biparietal diameter, head circumference, femur length, and abdominal circumference. The gestational age was based on the last menstrual period and the crown rump length in the first trimester ultrasound. The amniotic fluid index and the largest vertical dimension of the amniotic fluid pockets were measured and recorded $(<2 \mathrm{~cm}$ was recorded as oligohydraminose). The morphology, thickness, and site of the placenta were recorded.

\section{Color Doppler ultrasound}

The uterine artery, umbilical artery, and the middle cerebral artery were examined. Doppler velocimetery was performed at least three consecutive times in each artery. We measured mean resistive index, pulsitility index, peak systolic velocity, and end-diastolic velocity in each artery. The presence of notch in the uterine arteries was recorded if present.

Virtual touch tissue quantification and SWV measurement The SWV measurement was performed in the same sitting with the gray-scale and color Doppler examinations. The pregnant women were in the supine position and were asked to stop moving and breathing quietly during the measurement of the SWV. Plenty amount of gel was used to prevent mechanical artifacts. We used the rectangular ROI, void of identifiable areas of degeneration, 
Table 1 Number and age of females with normal and high-risk pregnancies

\begin{tabular}{|c|c|c|c|c|}
\hline & \multicolumn{2}{|c|}{ Second trimester (160 patients) } & \multicolumn{2}{|c|}{ Third trimester (310 patients ) } \\
\hline & No & Age & No & age \\
\hline Normal & $45(43.75 \%)$ & $23.4 \pm 6.4$ & $94(30.32 \%)$ & $24.4 \pm 2.3$ \\
\hline Hypertension & $11(6.87 \%)$ & $24.5 \pm 7.1$ & $36(11.61 \%)$ & $25.4 \pm 2.2$ \\
\hline Preeclampsia/eclampsia & $9(5.62 \%)$ & $24.8 \pm 6.5$ & $46(14.83 \%)$ & $27.4 \pm 5.6$ \\
\hline Diabetes & $13(8.12 \%)$ & $23.5 \pm 7.5$ & $17(5.48 \%)$ & $28.4 \pm 7.7$ \\
\hline Placenta previa & $8(5 \%)$ & $27.4 \pm 8.8$ & $11(3.54 \%)$ & $26.4 \pm 5.9$ \\
\hline Morbidly adherent placenta (MAP) & $5(3.12 \%)$ & $28.4 \pm 6.9$ & $15(4.83 \%)$ & $29.4 \pm 3.5$ \\
\hline Thyroid disease & $6(3.75 \%)$ & $33.4 \pm 2.4$ & $6(1.93 \%)$ & $28.4 \pm 2.1$ \\
\hline Renal disease & $6(3.75 \%)$ & $30.4 \pm 3.5$ & $7(2.25 \%)$ & $33.4 \pm 6.4$ \\
\hline Auto-immune disease & $7(4.37 \%)$ & $29.4 \pm 4.7$ & $8(2.58 \%)$ & $31.4 \pm 8.0$ \\
\hline Obesity & $12(7.5 \%)$ & $28.4 \pm 4.7$ & $26(8.38 \%)$ & $31.4 \pm 8.8$ \\
\hline Teen age & $19(11.87 \%)$ & $18.4 \pm 7.6$ & $21(6.77 \%)$ & $19.2 \pm 7.1$ \\
\hline Old primigravida & $12(7.5 \%)$ & $39.4 \pm 9.4$ & $17(5.48 \%)$ & $40.4 \pm 4.3$ \\
\hline Cardiac disorders & 7 (4.37\%) & $21.4 \pm 4.4$ & $6(1.93 \%)$ & $25.4 \pm 5.4$ \\
\hline
\end{tabular}

or calcification with a fixed dimension of $1.0 \mathrm{~cm} \times 0.5$ $\mathrm{cm}$. Shear wave velocity (SWV) was measured in at least five different ROIs for each placenta. The depth ranged from 1.7 to $7.5 \mathrm{~cm}$. The measurements were performed at different sites and depths of the placenta. Measurements were not performed at the site of cord insertion and at placental margins. Also, sites of large blood vessels were avoided. The interval between measurements was 4-7 s, depending on machine system cooling. The mean SWVs were calculated for each placenta, expressed in meters per second $(\mathrm{m} / \mathrm{s})$. The non-valid measurements were excluded, and at least five valid measurements were recorded.

\section{Statistical analysis}

We used the SPSS software (version 16.0, SPSS Inc.) for statistical analysis. The maximum and mean SWVs within the ROI were expressed as the mean of different measurements \pm standard deviation. Differences in age, gestational age, fetal weight, Doppler indices in uterine, umbilical and middle cerebral arteries, and the presence of a diastolic notch were evaluated using the MannWhitney $U$ test. The SWV data were correlated to Doppler indices using the Pearson correlation test.

Receiver operating characteristic curves were plotted to check the best SWE cutoff value which predicts the growth restriction or abnormal Doppler parameters, and we calculated the sensitivity, specificity, positive predictive value (PPV), and negative predictive value (NPV).

\section{Results}

Table 1 shows the number and age of patients involved in the study. The study included 139 females (29.5\%) with healthy pregnancy. The females with essential hypertension and preeclampsia were the largest group in the high-risk group including 82 patients in the third trimester $(26.4 \%$ of patients in the third trimester) and 20 patients in the second trimester $(12.5 \%$ of patients in the second trimester). Thirty pregnant females $(6.4 \%$ of the entire studied group) with diabetes mellitus (of all types) were involved in the study. Other major causes of high risk in the study were morbid obesity (38 patients, $8 \%$ of the study population), teenager females (40 patients, $8.5 \%$ ), and old primigravida (29 patients, $6.1 \%$ of the study population). Also, the study included 39 with abnormal placenta (either placenta previa or accreta), representing $8.2 \%$ of the study population. The study included 15 patients with auto-immune disease, all had systemic lupus erythematosus.

The SWV showed no significant difference between the placenta of normal pregnancies (Figs. 1 and 2) in the second and third trimesters $(0.85 \pm 0.43 \mathrm{~m} / \mathrm{s}$ and $0.89 \pm$ $0.57 \mathrm{~m} / \mathrm{s}$, respectively). The placenta of patients with preeclampsia/eclampsia had high SWV in the second and third trimesters $(2.13 \pm 1.48 \mathrm{~m} / \mathrm{s}$ and $2.23 \pm 1.48 \mathrm{~m} /$ s) with a highly significant difference from the normal placenta $(P<0.001)$ (Fig. 3). The SWV velocities in placentas of females with auto-immune disease, renal disease, and old primigravida were higher than those in the placenta of normal pregnancy, and the difference was statistically significant. The shear wave velocities in placentas of females with thyroid disease, obesity, teenagers, and cardiac disease showed no statistically significant difference with the SWVs in the placenta of females with normal pregnancy. In females with essential hypertension and diabetes, the SWV was significantly higher in the third trimester but not in the second trimester (Fig. 4; Table 2). 


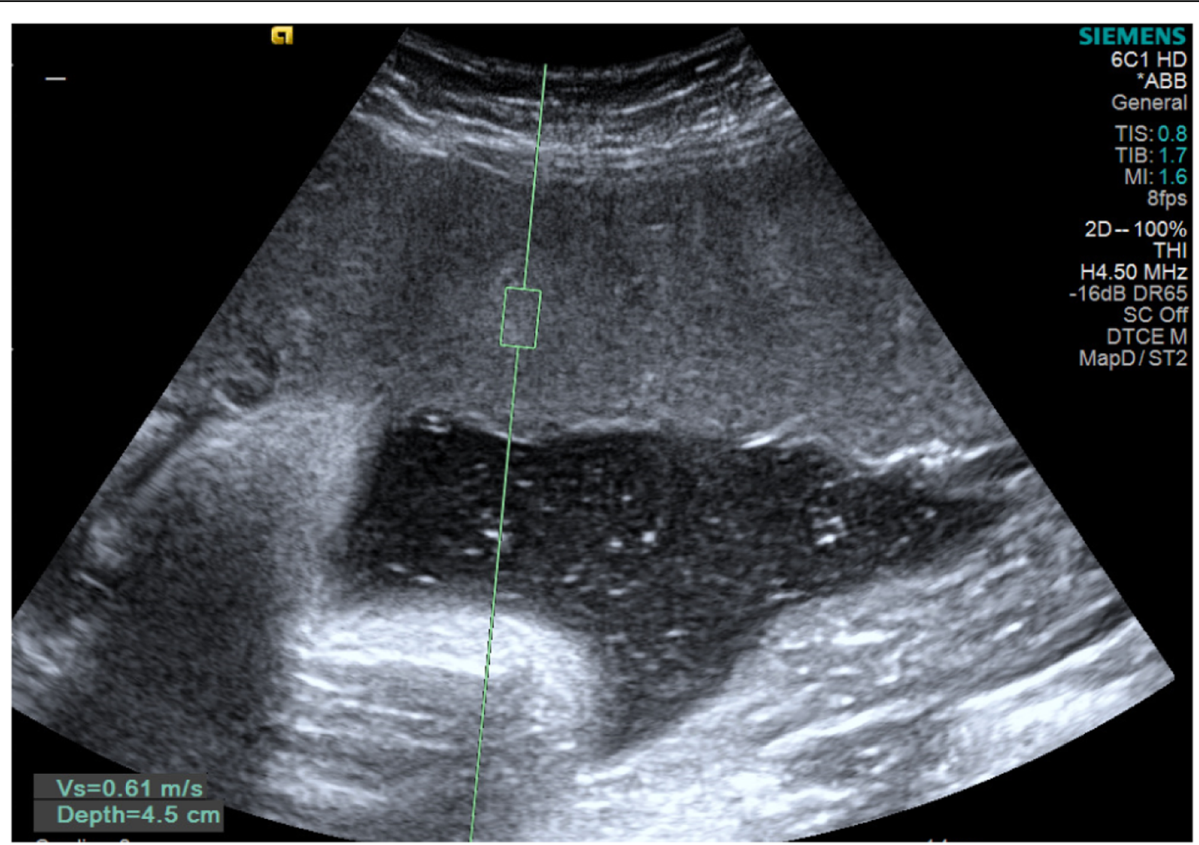

Fig. 1 Normal pregnancy aged 37 weeks. Normal anterior placenta, $S W=0.61 \mathrm{~m} / \mathrm{s}$, depth $4.5 \mathrm{~cm}$

The placentas with abnormal location (placenta previa) and penetration (placenta accreta) had higher SWV than the placentas of normal pregnancies (Fig. 5). The mean SWV for placenta previa was $1.1 \pm 0.74 \mathrm{~m} / \mathrm{s}$ and $1.3 \pm$ $0.81 \mathrm{~m} / \mathrm{s}$ in the second and third trimesters, respectively, with a mildly significant difference with the normal placenta. The placenta accreta shows high mean SWV in the second and third trimesters $(1.6 \pm 0.65 \mathrm{~m} / \mathrm{s}$ and $1.961 .6 \pm 0.65$ respectively) which differed significantly $(P<0.001)$ from SWV in the normal placenta in the second and third trimesters (Table 2).

In the current study, 19 of the patients with preeclampsia had growth restriction and the rest (36 patients) had normal growth. The min SWV, max SWV,

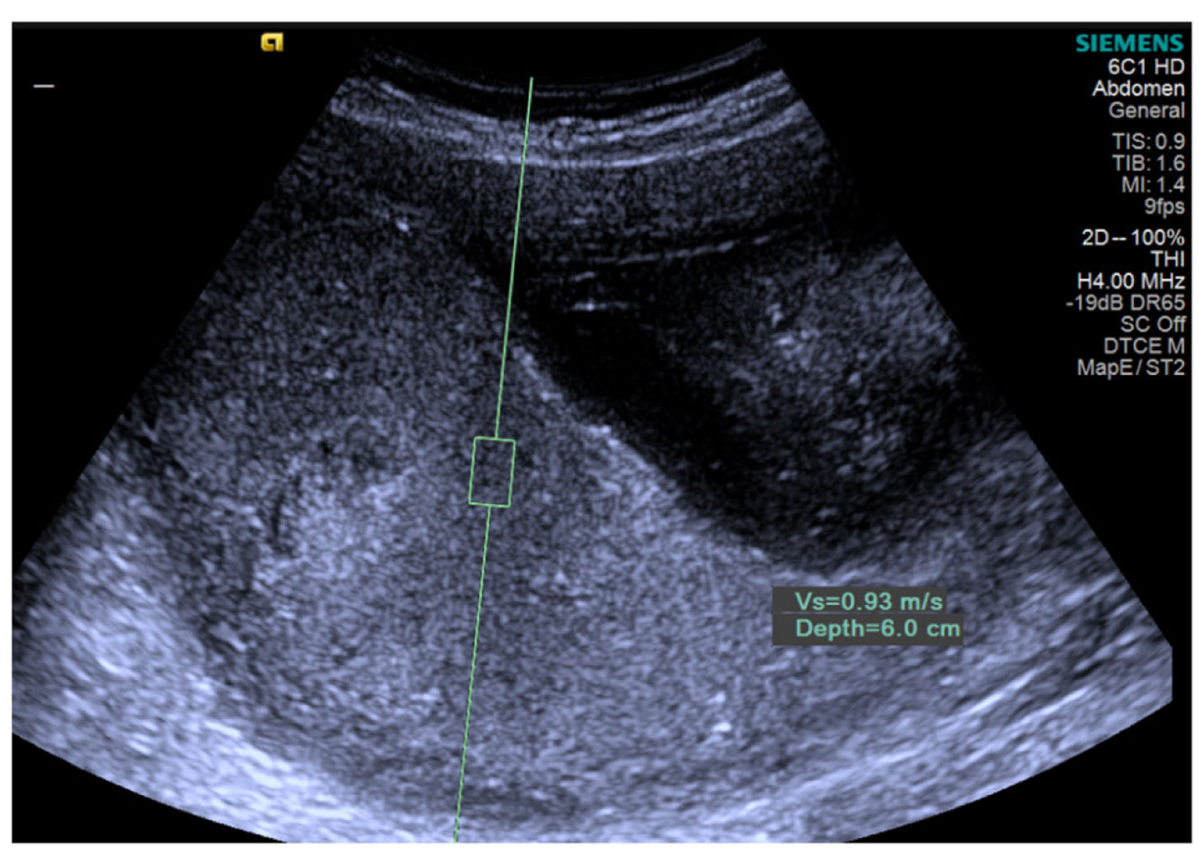

Fig. 2 Normal pregnancy aged 37 weeks. Normal posterior placenta, $S W=0.93 \mathrm{~m} / \mathrm{s}$, depth $6.0 \mathrm{~cm}$ 

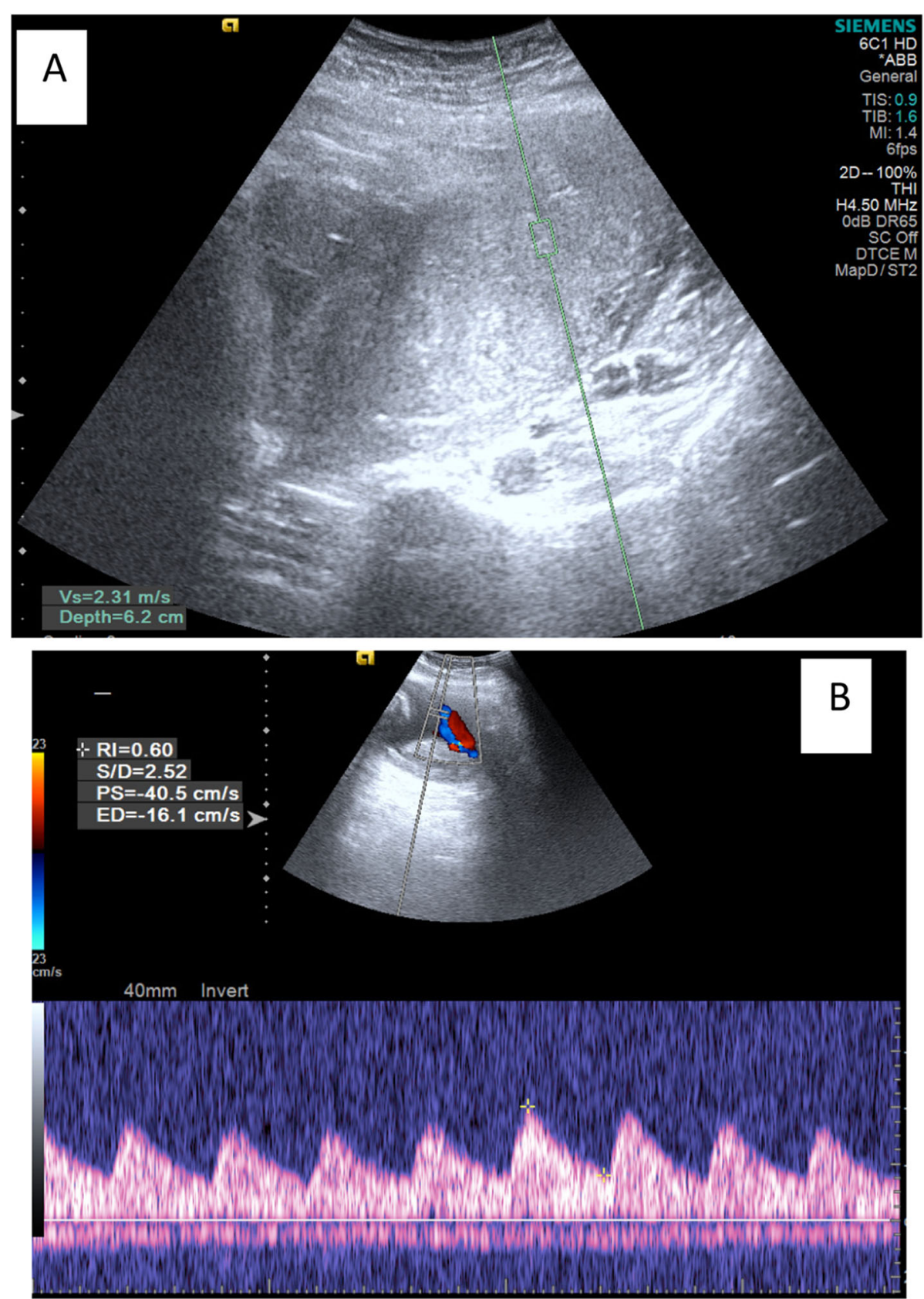

Fig. 3 Pregnancy with preeclampsia, gestational age 33 weeks, and estimated fetal. Weight $1.9 \mathrm{~kg}$. a Grade II posterior placenta with SWV = 2.31 $\mathrm{m} / \mathrm{s}$, depth $6.2 \mathrm{~cm}$. b Normal Doppler flow in the umbilical artery with RI 0.6. In the current study, in the placenta of pregnancies complicated by preeclampsia, the SWV was higher than the normal placenta, even with normal Doppler flow

and mean SWV in placentas of females with preeclampsia/eclampsia were higher in cases complicated with growth restriction than in cases with normal growth $(P<0.001)$, and also, there was a positive correlation between the high SWV and the growth restriction (Table 3). The difference in SWV was more significant and more correlated with growth restriction than Doppler indices (Fig. 6).
Also, the min SWV, max SWV, and mean SWV in placentas of females with high-risk pregnancies were higher in cases of females with abnormal Doppler flow than in high-risk pregnancies with normal Doppler flow $(P<0.001$, Table 4$)$.

The area under the curve (AUC) for the diagnosis of preeclampsia and/or growth restriction in the studied population was based on mean SWV acquired from the 

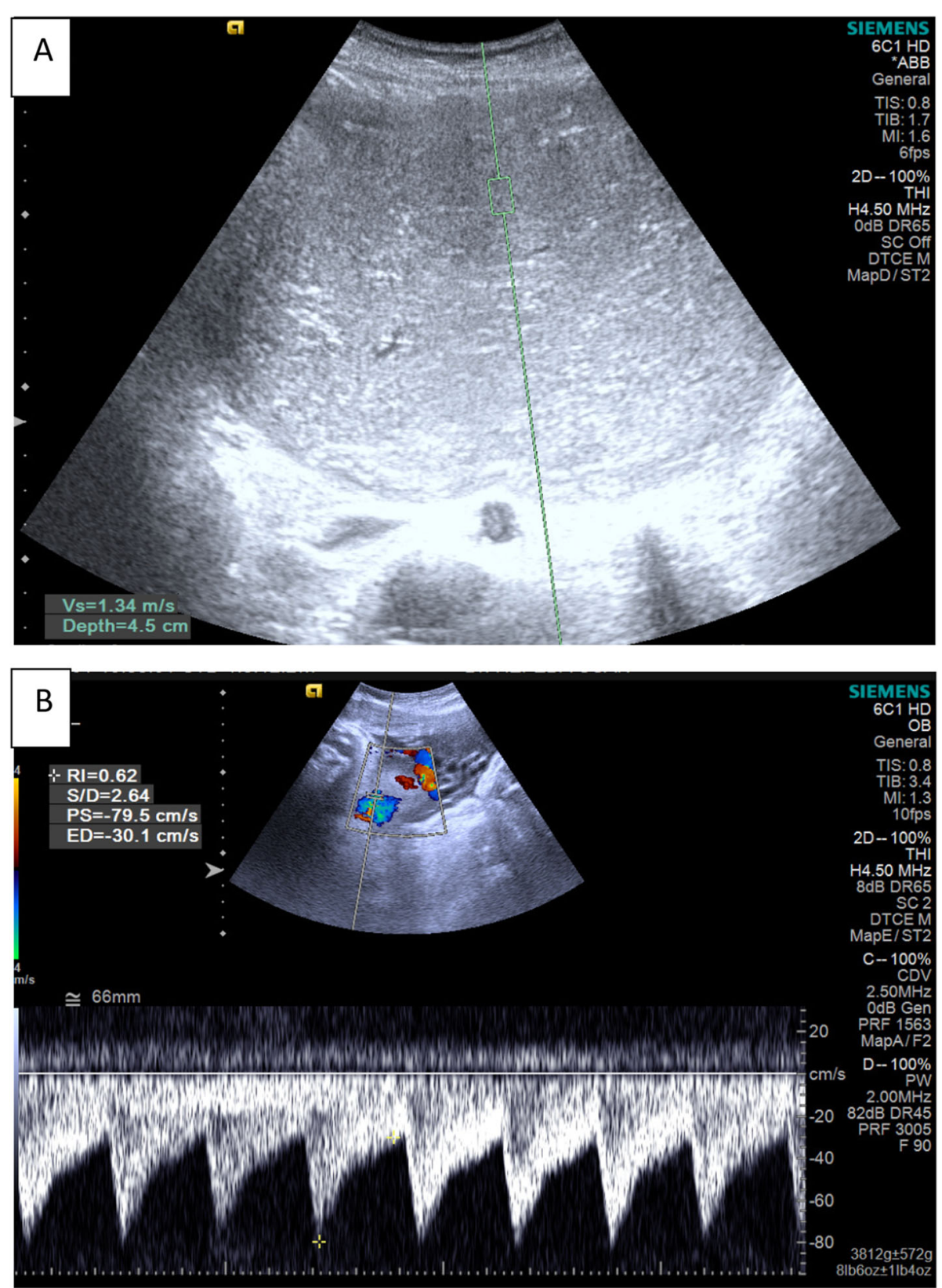

Fig. 4 Pregnancy with diabetes and macrosomia, gestational age 35 weeks, and estimated fetal. Weight $4.2 \mathrm{~kg}$. a SWV = $1.34 \mathrm{~m} / \mathrm{s}$, depth $4.5 \mathrm{~cm}$. b Normal flow in the umbilical artery. In the current, the pregnancies with diabetes showed only mild increased elasticity in the third trimester

placenta (Fig. 7). The cutoff value maximizing the accuracy of diagnosis was $1.35 \mathrm{~m} / \mathrm{s}$ (AUC, 0.906; 95\% confidence interval, 0.798-1.015); sensitivity, specificity, PPV, $\mathrm{NPV}$, and diagnostic accuracy of this cutoff value were $91.3 \%, 86.4 \%, 72.7 \%, 75.4 \%$, and $86.4 \%$, respectively.

\section{Discussion}

In the last few years, the elasticity of the placenta and SWV has been studied in the normal placenta [23, 24] and in pregnancies complicated with preeclampsia [25-
27], diabetes [28], fetal anomalies [21], and placenta accreta [29]. The normal placenta is a soft organ; it is softer than the breast and liver with the SWV in the normal placenta is less than the SWV in both organs [30, 31]. In a recent ex vivo study, Simon et al. suggested that the placental insufficiency alters the placental elasticity or the reverse. The changes which affect the placenta in different conditions like placental infarcts, sclerosis of the placental arterioles, excess fibrin deposition in the villi, and the change in the number of villi 
Table 2 Comparison of VTQ (SWV) in the second and third trimester pregnancies in normal and high-risk pregnancies

\begin{tabular}{|c|c|c|c|c|c|c|}
\hline & \multicolumn{3}{|c|}{ SWV in the second trimester group } & \multicolumn{3}{|c|}{ SWV in the third trimester } \\
\hline & Min-max & Mean \pm SD & $P$ value & Min-max & Mean \pm SD & $P$ value \\
\hline Normal & $0.59-1.46$ & $0.85 \pm 0.43$ & NA & $0.73-2.11$ & $0.89 \pm 0.57$ & NA \\
\hline Hypertension & $0.66-1.62$ & $0.95 \pm 0.65$ & 0.43 & $0.86-2.92$ & $1.23 \pm 0.72$ & 0.01 \\
\hline Preeclapsia/eclampsia & $1.26-3.72$ & $2.13 \pm 1.48$ & $<0.001$ & $1.34-4.12$ & $2.23 \pm 1.48$ & $<0.001$ \\
\hline Diabetes & $0.74-2.45$ & $0.94 \pm 1.21$ & 0.06 & $0.82-2.91$ & $1.3 \pm 0.81$ & $<0.05$ \\
\hline Placenta previa & $0.74-2.11$ & $1.1 \pm 0.74$ & 0.05 & $0.92-2.71$ & $1.6 \pm 0.81$ & 0.03 \\
\hline Morbidly adherent placenta (MAP) & $1.1-2.31$ & $1.6 \pm 0.65$ & 0.001 & $1.4-2.62$ & $1.96 \pm 0.71$ & 0.001 \\
\hline Thyroid disease & $0.73-1.63$ & $0.91 \pm 0.54$ & 0.53 & $0.67-1.73$ & $0.93 \pm 0.54$ & 0.47 \\
\hline Renal disease & $0.91-2.5$ & $1.51 \pm 0.65$ & $<0.05$ & $1.01-2.62$ & $1.41 \pm 0.66$ & $<0.05$ \\
\hline Auto-immune disease & $1.03-3.3$ & $1.98 \pm 0.71$ & $<0.001$ & $1.24-3.72$ & $1.98 \pm 0.71$ & $<0.001$ \\
\hline Obesity & $0.82-1.75$ & $0.93 \pm 0.56$ & 0.37 & $0.89-1.75$ & $0.99 \pm 0.71$ & 0.45 \\
\hline Teen age & $0.64-1.81$ & $0.83 \pm 47$ & 0.73 & $0.78-1.69$ & $0.89 \pm 63$ & 0.5 \\
\hline Old primigravida & $1.12-2.71$ & $1.35 \pm 0.64$ & 0.02 & $1.31-3.31$ & $1.55 \pm 0.59$ & 0.01 \\
\hline Cardiac disorders & $0.76-2.21$ & $0.92 \pm 0.54$ & 0.32 & $0.91-2.01$ & $0.92 \pm 0.34$ & 0.5 \\
\hline
\end{tabular}

will lead to change in biomechanical properties of the placenta and will affect its function [32]. The increase in placental thickness in cases with high body mass index (BMI) and diabetes may also increase the stiffness of the placenta and affect its function [33, 34].

In the current study, the mean SWV in the normal placenta in the second and third trimester pregnancies was $0.85 \pm 0.43 \mathrm{~m} / \mathrm{s}$ and $0.89 \pm 0.57 \mathrm{~m} / \mathrm{s}$, respectively, with no significant difference in placental elasticity between the second and third trimesters. Our results are in agreement with $\mathrm{Wu}$ et al. who reported no significant difference in SWV between the second and third trimesters, though they reported mildly higher velocities $(0.978$ $\pm 0.255 \mathrm{~m} / \mathrm{s}$ vs. $0.987 \pm 0.266 \mathrm{~m} / \mathrm{s}$ in the second and third trimesters, respectively).

Hypertensive disorders with pregnancy are a major cause of maternal and fetal morbidity and mortality. Abnormal placentas are presumed to play a role in the development of preeclampsia [22]. Our results showed that the placental stiffness expressed as high VTQ and SWV was significantly higher in preeclampsia than in normal pregnancies. Furthermore, the SWV was significantly higher in hypertensive patients with growth restriction than pregnancies with normal fetal growth. Akbas et al. [35] in a recent study including 156 patients found a significantly higher SWV in the placenta of pregnancies with growth restriction than pregnancies with normal growth, and they concluded that in the growth-restricted pregnancies, the placentas tend to be stiffer. Also, Sugitani et al. observed that the SWV in the placentas of hypertensive growth-retarded pregnancies was higher than that in normal placentas, but they studied ex vivo placentas [36]. Also, in a recent study, Saw et al. [37] studied the mechanical properties of 46 normal placentas and 43 growth-retarded placentas ex vivo and they found placentas of growth-retarded pregnancies slightly stiffer than normal placentas. The structural abnormalities of the placenta in preeclampsia are thought to result from inadequate and unsuccessful cytotrophoblast and trophoblast invasion of the myometrium associated with spiral artery remodeling, resulting in placental hypoxia, ischemia, syncytial knots, placental infarcts, vasculopathy, and placental erythroblastosis as well as excessive fibrin deposition. All these factors will lead to increase placental stiffness $[38,39]$.

In the current study, we found no significant difference in SWV between normal pregnancies and diabetic pregnancies in the second trimester and only mild increased elasticity in the third trimester. Our results are similar to those of Bildac et al. [40], who observed no significant difference between the SWV in the placenta of control and diabetic females between 24 and 28 weeks of gestations $(P>0.5)$. On the other hand, the relative increased stiffness and shear wave velocity in the third trimester can be explained by previous reports suggesting focal thickening of the trophoblastic basement membrane, villous immaturity, and ischemia of the placenta in diabetic pregnancies [41, 42].

Morbidly adherent placenta (MAP), with its three types, the accreta, increta, and percreta, is a significant risky condition which is now common after the increased number of cesarian sections. Currently, the first line for diagnosis of MAP is the ultrasonography and color Doppler ultrasound with reasonable sensitivity of $91 \%$ and specificity of $97 \%$ [43], and MRI is used only in questionable and inaccessible cases like posterior placenta and very obese females [44]. In the current study, the morbidly adherent placenta (MAP) had higher 


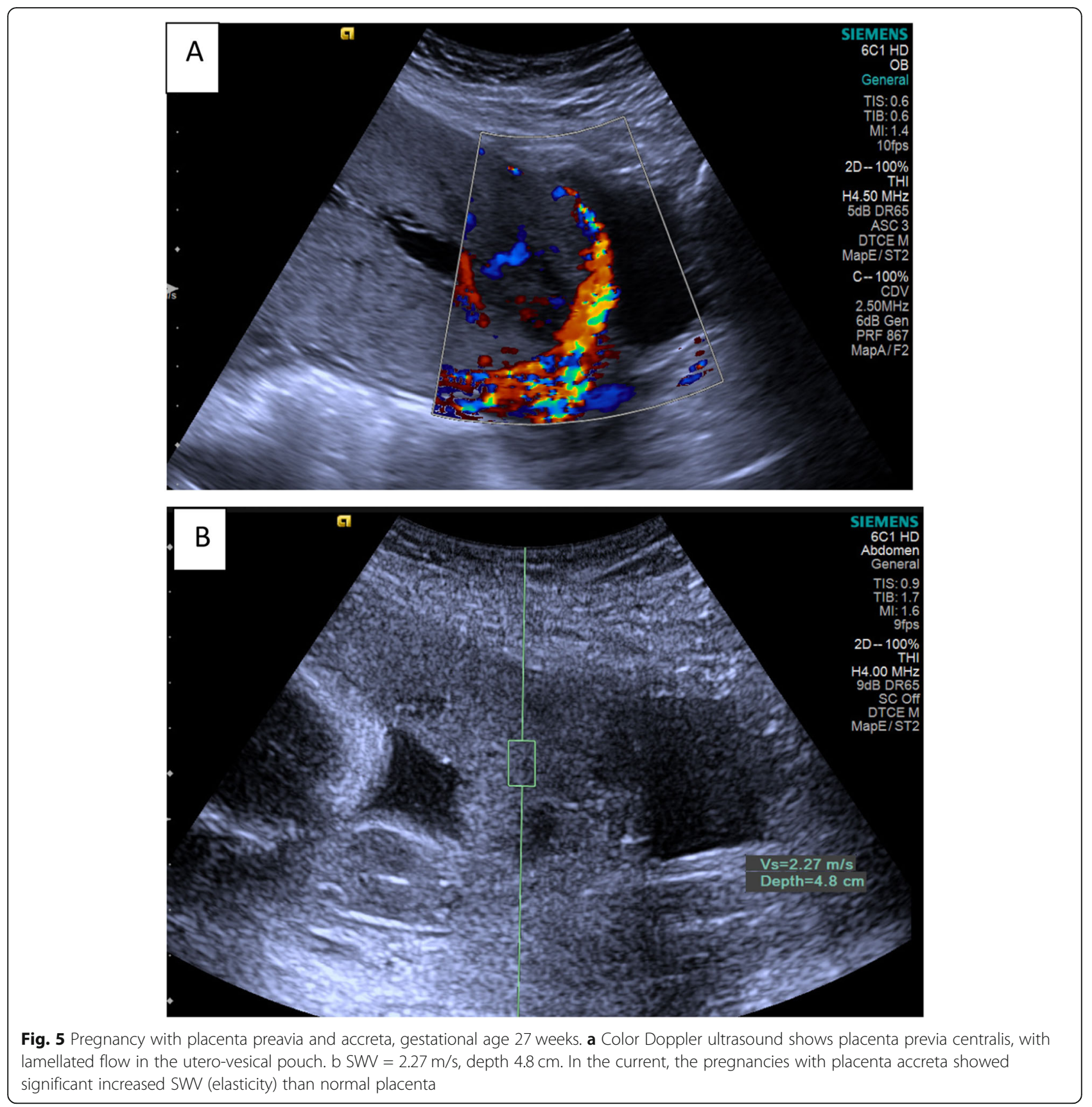

Table 3 Correlation between the mean SWV and Doppler indices in hypertensive disease (essential hypertension and preeclampsia/ eclampsia) with normal growth and with growth restriction

\begin{tabular}{|c|c|c|c|c|}
\hline & Hypertensive disease with normal growth & Hypertensive disease with growth restriction & $P$ value & $r$ value \\
\hline Min SWV & $0.66 \pm 0.45$ & $0.94 \pm 0.45$ & $<0.001$ & 0.654 \\
\hline Max SW & $2.1 \pm 0.96$ & $2.5 \pm 1.22$ & $<0.001$ & 0.745 \\
\hline Mean SWV & $1.21 \pm 0.76$ & $2.51 \pm 0.87$ & $<0.001$ & 0.701 \\
\hline Umbilical artery Rl & $0.65 \pm 0.12$ & $0.82 \pm 0.14$ & $<0.01$ & 0.352 \\
\hline Umbilical artery PI & $1.56 \pm 0.34$ & $2.7 \pm 0.87$ & 0.05 & 0.452 \\
\hline Uterine artery RI & $0.71 \pm 0.45$ & $0.87 \pm 0.11$ & $<0.01$ & 0.712 \\
\hline Uterine artery PI & $1.43 \pm 0.65$ & $2.51 \pm 0.65$ & $<0.05$ & 0.512 \\
\hline
\end{tabular}



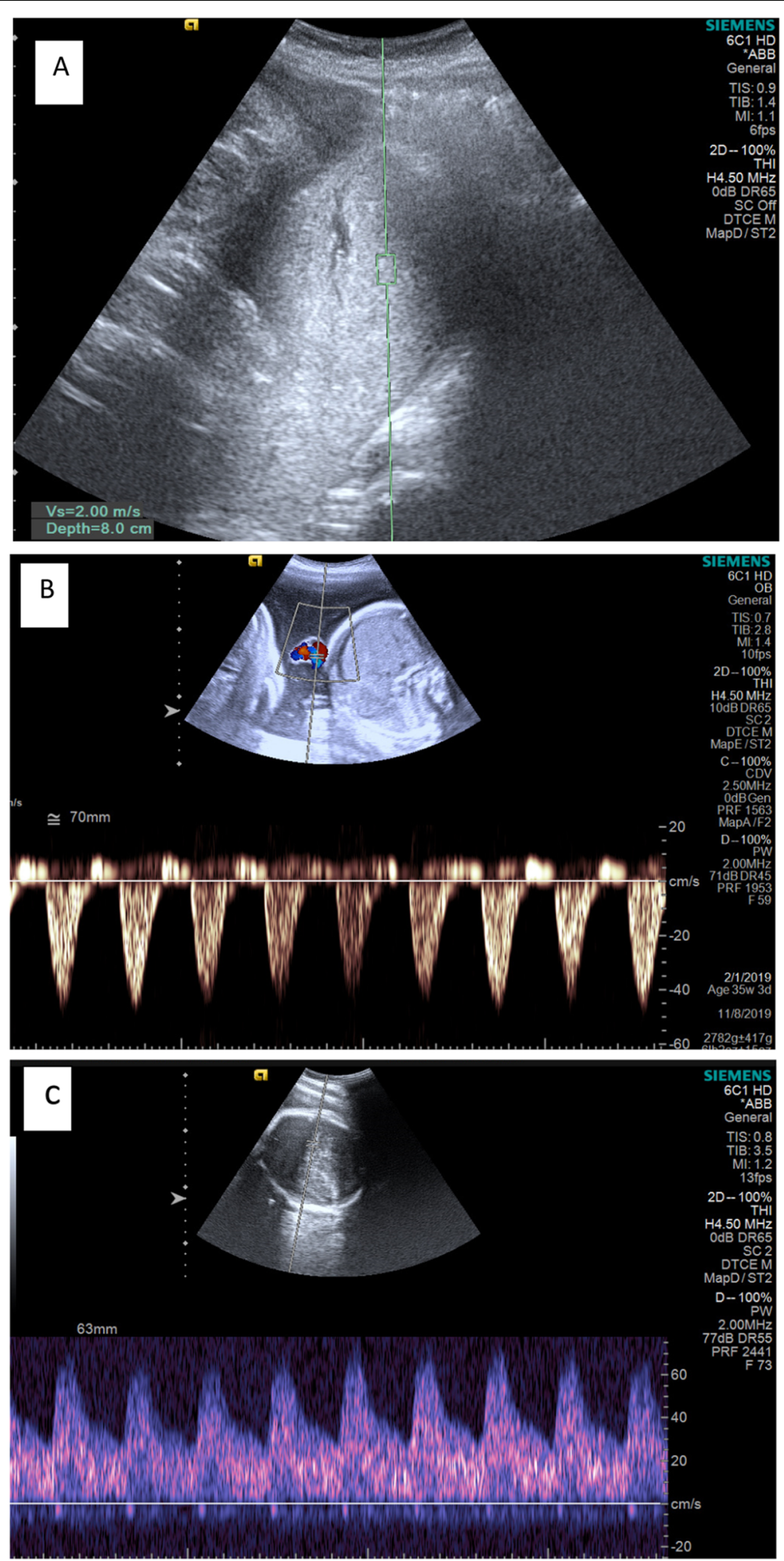

Fig. 6 Pregnancy with severe preeclampsia, gestational age 36 weeks, and estimated fetal. Weight $2.5 \mathrm{~kg}$. a SWV $=2.00 \mathrm{~m} / \mathrm{s}$, depth $8 \mathrm{~cm}$. b Reversed diastolic flow in the umbilical artery. $\mathbf{c}$ High diastolic flow in the middle cerebral artery (redistribution). In the current study, the SWV showed a strong correlation with the growth restriction and abnormal Doppler parameters 
Table 4 Comparison between SW in the placenta of high-risk pregnancy with normal and abnormal Doppler flow

\begin{tabular}{|c|c|c|c|c|}
\hline & High-risk group with normal Doppler & High-risk group with abnormal Doppler indices & $P$ value & $r$ value \\
\hline Min SWV & $0.71 \pm 0.65$ & $1.54 \pm 0.75$ & $<0.001$ & 0.754 \\
\hline Max SWV & $2.3 \pm 0.96$ & $2.9 \pm 1.43$ & $<0.001$ & 0.765 \\
\hline Mean SWV & $1.42 \pm 0.76$ & $2.62 \pm 0.87$ & $<0.001$ & 0.731 \\
\hline
\end{tabular}

SWV than normal placentas and placenta previa, and the difference of VTQ from the normal placenta was significant $(P=0.001)$. Our results are similar to those of Cim et al. [45] in a study which included 58 pregnant females with suspected MAP observed that the SWV in the placentas with abnormal attachment at operation was higher than that in normal placentas, and the difference was statistically significant $(P<0.001)$. Also, the elastography can be used to delineate the areas of the placenta with abnormal attachment [46], but it cannot determine the depth of invasion [47].

Based on the results of the present study, the cutoff value for prediction of preeclampsia and/or growth restriction was $1.35 \mathrm{~m} / \mathrm{s}$. In a recent study by Fujta et al. [26], the best cutoff value for prediction of preeclampsia was $1.188 \mathrm{~m} / \mathrm{s}$, and they concluded that below their cutoff value the risk of developing preeclampsia is considered low.

In the current study, we found high SWV in the placenta of old primigravida, and the difference from the normal placenta was significant. To the best of our knowledge, there were no previous reports about the effect of maternal age on placental elasticity. On the other hand, obesity and teen age had no effect on placental stiffness.

In the current study, the mean SWV in the placenta was higher in growth restriction, abnormal Doppler indices, preeclampsia, and auto-immune disease than other causes of high-risk pregnancy. Also, the mean shear wave velocity in placenta accreta was higher than that in placenta previae.

Our study has several limitations. We did not have histopathological examination of the placentas, and no correlation between placental micro-architecture and SWV was made. No correlation was studied between the sites of ROIs and the SWVs. We placed the ROI randomly. No intra-observer or inter-observer variations were studied. Also, we did not correlate the VTQ with morphological characters of the placenta like grade, thickness, and presence of calcification. The sample size for some diseases like thyroid disease with pregnancy was relatively small.

\section{Conclusion}

Shear wave velocity measurement as the quantitative parameter of ARFI elastography reflects the placental

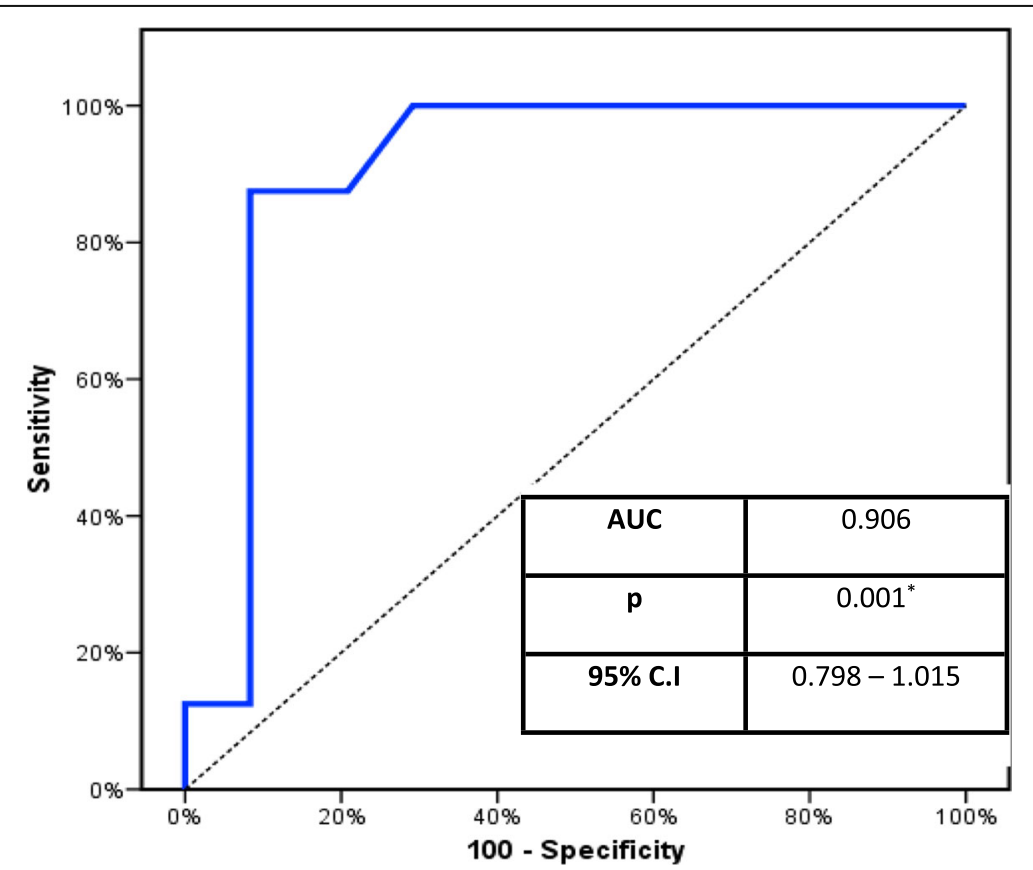

Fig. 7 Receiver operating characteristic curve for prediction of preeclampsia and/or growth restriction and abnormal Doppler. The cutoff values for predicting preeclampsia and the area under the curve were $1.35 \mathrm{~m} / \mathrm{s}$ and 0.906 , respectively 
elasticity in normal and high-risk pregnancies. The SWV increases in conditions like hypertension, preeclampsia, maternal renal disease, and diabetes and reflects the structural and biomechanical abnormalities in such diseases. High shear wave velocity correlates with the incidence of growth restriction and abnormal Doppler parameters especially in the hypertensive disease. The VTQ can be used as a complementary diagnostic and prognostic tool in high-risk pregnancy.

\section{Abbreviations}

ARFI: Acoustic radiation force impulse; SWV: Shear wave velocity; VTQ: Virtual touch quantification; PPV: Positive predictive value; NPV: Negative predictive value; MAP: Morbidly adherent placenta; SWE: Shear wave elastography; ROI: Region of interest; qSWE: Quantitative shear wave elastography

\section{Acknowledgements}

None

\section{Authors' contributions}

$\mathrm{MH}$ conceived of the study, performed ultrasound examination, participated in its design and coordination, drafted the manuscript, and carried out radiological results. AZ participated in the design of the study and sequence alignment and helped in drafting the results. The authors have read and approved the final manuscript.

\section{Funding}

None

\section{Availability of data and materials}

Data are available upon reasonable request.

\section{Ethics approval and consent to participate}

The study was approved by the local ethics committee of Tanta University, and informed written consent was signed by all patients.

\section{Consent for publication}

All patients included in this research gave written informed consent to publish the data contained within this study.

\section{Competing interests}

Nothing to declare

Received: 21 May 2020 Accepted: 26 June 2020

Published online: 22 July 2020

\section{References}

1. Kuhlmann RS, Warsof S (1996) Ultrasound of the placenta. Clin Obstet Gynecol 39:519-534

2. Smith GC, Smith MF, McNay MB, Fleming JE (1997) The relation between fetal abdominal circumference and birth weight: findings in 3512 pregnancies. Br. J. Obstet. Gynaecol. 104(2):186-190

3. Bricker $\mathrm{L}$, Medley N, Pratt JJ. Routine ultrasound in late pregnancy (after 24 weeks' gestation). Cochrane Database Syst 2015 . Rev. 6, CD001451

4. Chauhan SP, Rouse DJ, Ananth CV, Magann EF, Chang E, Dahlke JD et al (2013) Screening for intrauterine growth restriction in uncomplicated pregnancies: time for action. Am. J. Perinatol. 30(1):33-39

5. Habibi A, Davutoglu A, Kandemirli SG, Alan M, KalyoncuUcar A, Zeytun P et al (2017) In vivo assessment of placental elasticity in intra uterine growth restriction by shear wave elastography. Eur J Radiol. 97:16-20

6. Kilic F, Kayadibi Y, Yuksel MA, Ustabasioglu FE, Oncul M, Madazli R et al (2015) Shear wave elastography of placenta: in vivo quantitation of placental elasticity in preeclampsia. Diagn Interv Radiol. 21(3):202-207

7. Landau LD, Lipshitz EM. Theory of elasticity, 3rd Edition, 1970: 1-172.

8. Zhu Y, Jia XH, Zhou W, Zhan WW, Zhou JQ (2020 Mar 18) Qualitative evaluation of virtual touch imaging quantification: a simple and useful method in the diagnosis of breast lesions. Cancer Manag Res. 12:2037-2045. https://doi.org/10.2147/CMAR.S241815
9. Romeih MAE, Ebeed AE. Sabry IM. Value of adding shear wave elastography to routine breast ultrasound examination in assessment of solid breast lesions. The Egyptian Journal of Radiology and Nuclear Med Volume 49, Issue 2, June 2018, Pages 553-563

10. Ippolito D, Galimberti S, Leni D, Vacirca F, Nasr A, Bragazzi NL, Spiga S, Schiavone V, Pincelli Al, Garancini M, Leone BE, Pagni F. Use of shear wave elastography in the sonographic triage of thyroid nodules: feasibility study in a series of lesions already selected for fine needle aspiration. J Ultrasound Med. 2019 Jul;38(7):1713-1720. doi: https://doi.org/10.1002/jum.14857. Epub 2018 Nov 27.

11. Abdelrahman Sherif F, Fatma AH, Mohsen E et al (2015) Ultrasound elastography in diagnostic evaluation of indeterminate thyroid nodules. Egypt J Radiol Nucl Med 49(3):639-648

12. Xiang LH, Fang Y, Wan J, Xu G, Yao MH, Ding SS, Liu H, Wu R (2019 Dec) Shear-wave elastography: role in clinically significant prostate cancer with false-negative magnetic resonance imaging. Eur Radiol. 29(12):6682-6689. https://doi.org/10.1007/s00330-019-06274-w

13. Gatos I, Drazinos P, Yarmenitis S, Theotokas I, Zoumpoulis PS. Comparison of sound touch elastography, shear wave elastography and vibrationcontrolled transient elastography in chronic liver disease assessment using liver biopsy as the "reference standard". Ultrasound Med Biol. 2020;46(4): 959-971. doi: https://doi.org/10.1016/j.ultrasmedbio.2019.12.016. Epub 2020 Jan 23.

14. Farmakis SG, Buchanan PM, Guzman MA, Hardy AK, Jain AK, Teckman JH. Shear wave elastography correlates with liver fibrosis scores in pediatric patients with liver disease. Pediatr Radiol. 2019 Dec;49(13):1742-1753. doi: https://doi.org/10.1007/s00247-019-04493-3. Epub 2019 Aug 15.

15. Zaki M, Hazem M, Elsamman M (2019) Shear wave elastography in assessment of liver stiffness and prediction of gastro-esophageal varices in patients with liver cirrhosis. Egypt J Radiol Nucl Med 50:16. https://doi.org/ 10.1186/s43055-019-0015

16. Gennisson JL. Deffieux T, Fink M. Tanter M. Ultrasound elastography: principles and techniques. Diagnostic and Interventional Imaging Volume 94, Issue 5, May 2013, Pages 487-495

17. Sigrist RMS, Liau J, Kaffas AE, Chammas MC, Willmann JK (2017) Ultrasound elastography: review of techniques and clinical applications. Theranostics 7(5):1303-1329. https://doi.org/10.7150/thno.18650

18. Cosgrove DO, Berg WA, Dore CJ et al (2012) Shear wave elastography for breast masses is highly reproducible. Eur Radiol 22:1023-1032

19. Evans A, Whelehan P, Thomson K et al (2010) Quantitative shear wave ultrasound elastography: initial experience in solid breast masses. Breast Cancer Res

20. Ohmaru T, Fujita Y, Sugitani M, Shimokawa M, Fukushima K, Kato K (2015 Aug) Placental elasticity evaluation using virtual touch tissue quantification during pregnancy. Placenta. 36(8):915-920. https://doi.org/10.1016/j. placenta.2015.06.008

21. Alan B, Göya C, Tunç S, Teke M, Hattapoğlu S. Assessment of placental stiffness using acoustic radiation force impulse elastography in pregnant women with fetal anomalies. Korean J Radiol. 2016 Mar-Apr;17(2):218-23. doi: 0.3348/kj.2016.17.2.218.

22. Karaman E, Arslan H, Cetin O, Sahin HG, Bora A, Yavuz A, Elasan S, Akbudak ! (2016 Nov) Comparison of placental elasticity in normal and pre-eclamptic pregnant women by acoustic radiation force impulse elastosonography. J Obstet Gynaecol Res. 42(11):1464-1470. https://doi.org/10.1111/jog.13078

23. Altunkeser A, Alkan E, Günenç O, Tolu I, Körez MK. Evaluation of a healthy pregnant placenta with shear wave elastography. Iran J Radiol. 2019 January; 16(1):e68280. doi: 0.5812/iranjradiol.68280.

24. Wu S, Nan R, Li Y, Cui X, Liang X, Zhao Y. Measurement of elasticity of normal placenta technique. Ultrasonography. 2016 Jul;35(3):253-257.

25. Cimsit C, Yoldemir T, Akpinar IN (2015) Shear wave elastography in placental dysfunction: comparison of elasticity values in normal and preeclamptic pregnancies in the second trimester. J Ultrasound Med. 34:151-159

26. Fujita YA, Nakanishi TO, Sugitani M, Kato K (2019) Placental elasticity as a new non invasive predictive marker of pre-eclampsia. Ultrasound in Med. \& Biol 45(1):93-97

27. Alan B, Tunç S, Agacayak E, Bilici A (2016) Diagnosis of pre-eclampsia and assessment of severity through examination of the placenta with acoustic radiation force impulse elastography. International Journal of Gynecology and Obstetrics 135:43-46

28. Yuksel MA, Kilic F, Kayadibi Y, Alici Davutoglu E, Imamoglu M, Bakan S, Mihmanli I, Kantarci F, Madazli R. Shear wave elastography of the placenta 
in patients with gestational diabetes mellitus. J Obstet Gynaecol. 2016;36(5): 585-588. doi: https://doi.org/10.3109/01443615.2015.1110120. Epub 2016 Mar 25.

29. Bayramoğlu Tepe N, Gelebek Yilmaz F, Bozdag Z, Uğur MG (2020 Mar 9) Subgroup analysis of accreta, increta and percreta cases using acoustic radiation force impulse elastography. J Obstet Gynaecol Res. https://doi.org/ $10.1111 /$ jog. 14229

30. Golatta M, Schweitzer-Martin M, Harcos A, Schott S, Junkermann H, Rauch G, et al. Normal breast tissue stiffness measured by a new ultrasound technique: Virtual touch tissue imaging quantification (VTIQ). Eur J Radiol. 2013;82(11):e676-e679. doi: https://doi.org/10.1016/j.ejrad.2013.06.029. [PubMed: 23932637]

31. Fontanilla T, Canas T, Macia A, Alfageme M, Gutierrez Junquera C, Malalana A, et al. Normal values of liver shear wave velocity in healthy children assessed by acoustic radiation force impulse imaging using a convex probe and a linear probe. Ultrasound Med Biol. 2014;40(3):470-477. doi: https://doi. org/10.1016/j.ultrasmedbio.2013.10.024. [PubMed:24361222].

32. Simon EG, Calle' S, Perrotin F, Remenieras J-P, Measurement of shear wave speed dispersion in the placenta by transient elastography: a preliminary ex vivo study. PLoSONE 2108; 13(4): e0194309. https://doi.org/10.1371/ journal.pone.0194309

33. Saha S, Biswas S, Mitra D, Adhikari A, Saha C. Histologic and morphometric study of human placenta in gestational diabetes mellitus. Ital J Anat Embryol. 2014;119(1):1-9. [PubMed: 25345070].

34. Yuksel MA, Kilic F, Kayadibi Y, Alici Davutoglu E, Imamoglu M, Bakan S, et al. Shear wave elastography of the placenta in patients with gestational diabetes mellitus. J Obstet Gynaecol. 2016;36(5):585-588. doi:https://doi.org/ 10.3109/01443615.2015.1110120. [PubMed: 27012734]

35. Akbas M, Koyuncu FM, Artunic-Ukumen B (2019) Placental elasticity assessment by point shear wave elastography in pregnancies with intrauterine growth restriction. Journal of Perinatal Medicine 47(8):841-846

36. Sugitani M, Fujita Y, Yumoto Y, Fukushima K, Takeuchi T, Shimokawa M et al (2013) A new method for measurement of placental elasticity: acoustic radiation force impulse imaging. Placenta 34:1009-1013

37. Saw SN, Low JYR, Ong MHH, Poh YW, Mattar CNZ, Biswas A, Yap CH (2018 Jul) Hyperelastic mechanical properties of ex vivo normal and intrauterine growth restricted placenta. Ann Biomed Eng. 46(7):1066-1077. https://doi. org/10.1007/s10439-018-2019-5

38. Devisme L, Merlot B, Ego A, Houfflin-Debarge V, Deruelle P, Subtil D (2013) A case-control study of placental lesions associated with pre-eclampsia. Int J Gyneacol Obstet 120:165-168

39. Hottor B, Bosio P, Waugh J et al (2010) Variation in composition of the intervillous space lining in term placentas of mothers with pre-eclampsia. Placenta 31:409-417

40. Bildac TB, Çevik H, Aksan esteli G, Tavasl B, Özdoğan s. Placental elasticity on patients with gestational diabetes: single institution experience. J Chin Med Assoc, 80 (2017), pp. 717-720

41. Salge AK, Rocha KM, Xavier RM, Ramalho WS, Rocha EL, Guimaraes JV, et al. Macroscopic placental changes associated with fetal and maternal events in diabetes mellitus. Clinics (Sao Paulo) 2012.67:1203-1208.

42. Madazli R, Tuten A, Calay Z, Uzun H, Uludag S, Ocak V. The incidence of placental abnormalities, maternal and cord plasma malondialdehyde and vascular endothelial growth factor levels in women with gestational diabetes mellitus and nondiabetic controls. Gynecologic and Obstetric Investigation 2008; 65:227-232.

43. D'Antonio F, lacovella C, Bhide A (2013) Prenatal identification of invasive placentation using ultrasound: systematic review and meta-analysis. Ultrasound Obstet Gynecol 42:509-517

44. D'Antonio F, lacovella C, Palacios-Jaraquemada J, Bruno CH, Manzoli L (2014) Bhide A. Prenatal identification of invasive placentation using magnetic resonance imaging: systematic review and meta-analysis Ultrasound in Obstetrics \& Gynecology 44(1):8-16

45. Cim N, Tolunay HE, Boza B, Arslan H, Ates C, liki I, Tezcan FM, Yildızhan R, Sahin HG, Yavuz A (2018) Use of ARFI elastography in the prediction of placental invasion anomaly via a new Virtual Touch Quantification Technique. J Obstet Gynaecol. 38(7):911-915. https://doi.org/10.1080/ 01443615.2018.1433646

46. Davie A, Wong WL, Clapham T, Angstetra D, Narayan R. Could elastography be used in the prediction of morbidly adherent placentation?, case reports in obstetrics and gynecology Volume 2016, Article ID 4909431, 3 pages https://doi.org/10.1155/2016/4909431
47. Bayramoğlu Tepe N, Gelebek Yilmaz F, Bozdag Z, Uğur M (2020 Mar 9) Subgroup analysis of accreta, increta and percreta cases using acoustic radiation force impulse elastography. J Obstet Gynaecol Res. https://doi.org/ 10.1111/jog.14229

\section{Publisher's Note}

Springer Nature remains neutral with regard to jurisdictional claims in published maps and institutional affiliations.

\section{Submit your manuscript to a SpringerOpen ${ }^{\circ}$ journal and benefit from:}

- Convenient online submission

- Rigorous peer review

- Open access: articles freely available online

- High visibility within the field

- Retaining the copyright to your article

Submit your next manuscript at $\boldsymbol{\nabla}$ springeropen.com 